\title{
Astrophysical plasma diagnostics through analysis of Ar I line shape characteristics
}

\author{
V. Milosavljević ${ }^{1,2}$ and S. Djeniže $\mathrm{e}^{1,2,3}$ \\ ${ }^{1}$ Faculty of Physics, University of Belgrade, PO Box 368, Belgrade, Serbia \\ 2 Isaac Newton Institute of Chile, Yugoslavia Branch, Belgrade, Serbia \\ ${ }^{3}$ Hungarian Academy of Sciences, Budapest, Hungary
}

Received 30 January 2003 / Accepted 15 April 2003

\begin{abstract}
On the basis of five accurately recorded neutral argon (ArI) line shapes (in the $4 \mathrm{~s}-5 \mathrm{p}$ transition) we have recovered the basic plasma parameters i.e. electron temperature $(T)$ and electron density $(N)$ using our new line deconvolution procedure in the case of three different plasmas created in a linear, low-pressure, pulsed arc discharge. The mentioned plasma parameters have also been measured using independent experimental diagnostic techniques. An excellent agreement has been found among the two sets of obtained parameters. This recommends our deconvolution procedure for plasma diagnostic purposes, especially in astrophysics where direct measurements of the main plasma parameters $(T$ and $N)$ are not possible. On the basis of the observed asymmetry of the Stark broadened line profile we have obtained not only its ion broadening parameter $(A)$ which is caused by the influence of the ion microfield on the line broadening mechanism but also the influence of the ion-dynamical effect $(D)$ on the line shape. The separate electron $\left(W_{\mathrm{e}}\right)$ and ion $\left(W_{\mathrm{i}}\right)$ contributions to the total Stark width, which have not been measured so far, have also been obtained and represent the first experimental data in this field. We have found a stronger influence of the ion contribution to the Ar I line profiles than the existing theoretical approximation provides. This is of importance for astrophysical plasma modeling and diagnostics.
\end{abstract}

Key words. plasmas - line: profiles - atomic data

\section{Introduction}

The presence of the neutral argon (Ar I) spectral lines has been discovered in various cosmic light sources in the last few years. Recently, Weaver et al. (2002) have referred to the presence of Ar I lines in the spectra of long-period comets. The Ar I absorption lines have been detected in the spectra of the quasar Q0347-3819 (Levshakov et al. 2002) and PG $1259+593$ (Richter et al. 2001). In the studies by Friedman et al. (2000), Jenkins et al. (2000), Kruk et al. (2002) and Lehner et al. (2002) the absorptions in the ArI lines were presented. Argon is detected in the spectrum of the damped $\mathrm{Ly}_{\alpha}$ system of IZw 18 (Levshakov et al. 2001). Mallouris et al. (2001) refer to the presence of ArI lines in the spectrum of the Wolf-Rayet binary SK 108. Thus, the ArI spectral line shapes represent important sources of information about the physical conditions in the place of birth of the radiation, especially since the launch of the Hubble space telescope.

In our work we applied our line deconvolution procedure (Milosavljević \& Poparić 2001) to five precisely recorded Ar I line profiles. The basic plasma parameters, i.e. electron

Send offprint requests to: V. Milosavljević, e-mail: vladimir@ff.bg.ac.yu temperature $\left(T^{\mathrm{D}}\right)$ and electron density $\left(N^{\mathrm{D}}\right)$ have been obtained, using our line deconvolution procedure, in the case of three different plasmas created in a linear, low-pressure, pulsed arc discharge in helium-argon and hydrogen-argon mixtures. To our knowledge, our results of the $T$ and $N$ values have been the first published data obtained directly from the line profile, using a deconvolution procedure. Plasma parameters have also been measured ( $T^{\exp }$ and $N^{\exp }$ ) using independent, wellknown, experimental diagnostical techniques. Excellent agreement has been found within the two sets of the obtained parameters $\left(T^{\mathrm{D}}\right.$ and $T^{\exp }$; and $N^{\mathrm{D}}$ and $\left.N^{\text {exp }}\right)$. This recommends our deconvolution procedure for plasma diagnostical purposes, especially in astrophysics where direct measurements of the plasma parameters $(T$ and $N)$ are not possible. The method is applicable for optically thin plasmas. For the optically thick plasmas the situation is more complicated because of very weak asymmetry of the spectral line profile caused by selfabsorption.

In plasmas with electron densities higher than $10^{21} \mathrm{~m}^{-3}$, where the Stark effect begins to play an important role in the Ar I spectral line broadening, the Stark broadening characteristics can also be used for plasma diagnostical purposes. However, the existing experimental Ar I Stark width data 
(Lesage \& Fuhr 1999; NIST 2002; Konjević et al. 2002, and references therein) present only the sum of the electron $\left(W_{\mathrm{e}}\right)$ and ion $\left(W_{\mathrm{i}}\right)$ contributions to the total Stark width $\left(W_{\mathrm{t}}\right)$ without any possibility for their separation. The $W_{\mathrm{e}}$ and $W_{\mathrm{i}}$ Ar I values presented here are the first data, in this field, separated from the measured total Stark width by using the line deconvolution procedure described by Milosavljević \& Poparić (2001) which have already been applied for some He I, Ne I, Ar I and Kr I lines (Milosavljević \& Djeniže 2002a,b,c, 2003). A significant number of experimental studies have been dedicated to the Ar I total Stark FWHM (full-width at half intensity maximum, $W_{\mathrm{t}}$ ) investigations of the $4 \mathrm{~s}-5 \mathrm{p}$ transition. However, only one study (Griem 1974) contains theoretical $W_{\mathrm{t}}, W_{\mathrm{e}}$ and $W_{\mathrm{i}}$ values in the $4 \mathrm{~s}-5 \mathrm{p}$ transition. In this paper we are presenting the measured Stark broadening parameters of the $415.86 \mathrm{~nm}$, $416.42 \mathrm{~nm}, 419.83 \mathrm{~nm}, 420.07 \mathrm{~nm}$ and $426.63 \mathrm{~nm}$ Ar I spectral lines (in the $4 \mathrm{~s}-5 \mathrm{p}$ transition) at about $16000 \mathrm{~K}$ electron temperature and at about $7.0 \times 10^{22} \mathrm{~m}^{-3}$ electron density. The used $T$ values are typical for many cosmic light sources. On the basis of the observed Ar I line profile asymmetry, the characteristics of the ion contribution to the total Stark $F W H M\left(W_{\mathrm{t}}\right)$, expressed as a function of the ion contribution parameter $(A)$ and iondynamical effect $(D)$ have also been obtained. As an optically thin plasma source we have used a linear, low-pressure, pulsed arc operated in three various discharge conditions. Our $W_{\mathrm{t}}, W_{\mathrm{e}}$, $W_{\mathrm{i}}$ and $A$ values have been compared to all available theoretical and experimental Stark broadening parameters.

\section{Theoretical background and deconvolution procedure}

The total line Stark FWHM $\left(W_{\mathrm{t}}\right)$ is given as

$$
W_{\mathrm{t}}=W_{\mathrm{e}}+W_{\mathrm{i}}
$$

where $W_{\mathrm{e}}$ and $W_{\mathrm{i}}$ are the electron and ion contributions, respectively. For a non-hydrogenic, isolated neutral atom line the ion broadening is not negligible and the line profiles are described by an asymmetric $K$ function (see Eq. (6)). The total Stark width $\left(W_{\mathrm{t}}\right)$ may be calculated from the equation (Griem 1974; Barnard et al. 1974; Kelleher 1981):

$W_{\mathrm{t}} \approx W_{\mathrm{e}}[1+1.75 A D(1-0.75 R)]$,

where

$R=\sqrt[6]{\frac{36 \pi e^{6} N}{(k T)^{3}}}$

is the ratio of the mean ion separation to the Debye length. $N$ and $T$ represent electron density and temperature, respectively. $A$ is the quasi-static ion broadening parameter (see Eq. (224) in Griem 1974) and $D$ is a coefficient of the iondynamical contribution with the established criterion:

$$
\begin{aligned}
& D=\frac{1.36}{1.75(1-0.75 R)} B^{-1 / 3} \text { for } \\
& B<\left(\frac{1.36}{1.75(1-0.75 R)}\right)^{3} \\
& \text { or } \\
& D=1 \text { for } B \geq\left(\frac{1.36}{1.75(1-0.75 R)}\right)^{3},
\end{aligned}
$$

where

$$
B=A^{1 / 3} \frac{4.03 \times 10^{-7} W_{\mathrm{e}}[\mathrm{nm}]}{(\lambda[\mathrm{nm}])^{2}}\left(N\left[\mathrm{~m}^{-3}\right]\right)^{2 / 3} \sqrt{\frac{\mu}{T_{\mathrm{g}}[\mathrm{K}]}}<1 ;
$$

is the factor with atom-ion perturber reduced mass $\mu$ (in amu) and gas temperature $T_{\mathrm{g}}$. When $D=1$ the influence of the iondynamic is negligible and the line shape is treated using the quasi-static ion approximation, described by Milosavljević \& Poparić (2001, and references therein):

$$
\begin{aligned}
& K(\lambda)=K_{\mathrm{o}}+K_{\max } \int_{-\infty}^{\infty} \exp \left(-t^{2}\right) \\
& \times\left[\int_{0}^{\infty} \frac{H_{R}(\beta)}{1+\left(2 \frac{\lambda-\lambda_{\mathrm{o}}-\frac{W_{\mathrm{G}}}{2 \sqrt{\ln 2}} t}{W_{\mathrm{e}}}-\alpha \beta^{2}\right)^{2}} \mathrm{~d} \beta\right] \mathrm{d} t .
\end{aligned}
$$

Here $K_{\mathrm{o}}$ is the baseline (offset) and $K_{\max }$ is the maximum intensity (for $\lambda=\lambda_{\mathrm{o}}$ ) (Milosavljević \& Poparić 2001). $H_{R}(\beta)$ is an electric microfield strength distribution function of normalized field strength $\beta=F / F_{\mathrm{o}}$, where $F_{\mathrm{o}}$ is the Holtsmark field strength. $A\left(\alpha=A^{4 / 3}\right)$ is the static ion broadening parameter and is a measure of the relative importance of ion and electron broadenings. $R$ is the ratio of the mean distance between the ions to the Debye radius (see Eq. (3)), i.e. the Debye shielding parameter and $W_{\mathrm{e}}$ is the electron width $(F W H M)$ in the $j_{\mathrm{A}, \mathrm{R}}$ profile (Griem 1974).

For the purpose of the deconvolution iteration process we need to know the value of $K$ (Eq. (6)) as a function of $\lambda$ for every group of parameters $\left(K_{\max }, \lambda_{\mathrm{o}}, W_{\mathrm{e}}, W_{\mathrm{G}}, R, A\right) . W_{\mathrm{G}}$ is defined in Eq. (2.3) of Milosavljević \& Poparić (2001). The used numerical procedure for solution of Eq. (6) is described in earlier publications (Milosavljević \& Poparić 2001; Milosavljević 2001; Milosavljević \& Djeniže 2002a).

From Eqs. (1-6) it is possible to obtain the plasma parameters $(N$ and $T)$ and the line broadening characteristics $\left(W_{\mathrm{t}}\right.$, $W_{\mathrm{e}}, W_{\mathrm{i}}, A$ and $\left.D\right)$. One can see that the ion contribution, expressed in terms of the $A$ and $D$ parameters directly determine the ion width $\left(W_{\mathrm{i}}\right)$ component in the total Stark width (Eqs. (1) and (2)).

This sophisticated deconvolution method, which allows direct determination of all six parameters by fitting the theoretical $K$-profile (6) to experimental data, requires a sufficient number of experimental points per line, and small statistical errors. The upper limits of numerical conditionality of this method are a minimum of twenty experimental points per line (within the range $-3 / 2 W_{\mathrm{e}}+\lambda_{\mathrm{o}}<\lambda<+3 / 2 W_{\mathrm{e}}+\lambda_{\mathrm{o}}$ ), and maximal statistical indeterminacy in intensity is $5 \%$ at every experimental point. Poor experimental measurements weaken the conditionality of the system of equations, and lead to non-applicability of this method. This has been concluded by testing the sensitivity of the algorithm by generating random statistical noise with Gaussian distribution in every point convolved by theoretical profiles. The fitting procedure with the $K$-convolution integral has also been tested using another set of experimental data (see Milosavljević \& Djeniže 2002a,b,c). The $K$ convolution integral is used for the analysis of our new data for many spectral 
Table 1. Various discharge conditions: $C$-bank capacity (in $\mu \mathrm{F}$ ), $U$-bank voltage (in $\mathrm{kV}$ ), $H$-plasma length (in $\mathrm{cm}$ ), $\Phi$-tube diameter (in mm), $P$-filling pressure (in Pa). $N^{\exp }$ (in $10^{22} \mathrm{~m}^{-3}$ ) and $T^{\exp }$ (in $10^{3} \mathrm{~K}$ ) denote experimental electron density and temperature, respectively obtained at a moment when the line profiles were analyzed. $N^{\mathrm{D}}\left(\right.$ in $\left.10^{22} \mathrm{~m}^{-3}\right)$ and $T^{\mathrm{D}}\left(\right.$ in $10^{3} \mathrm{~K}$ ) represent averaged electron density and averaged electron temperature obtained by using our line deconvolution procedure (Milosavljević \& Poparić 2001).

\begin{tabular}{ccccccccccc}
\hline \hline Working gases & Exp. & $C$ & $U$ & $H$ & $\Phi$ & $P$ & $N^{\exp }$ & $N^{\mathrm{D}}$ & $T^{\exp }$ & $T^{\mathrm{D}}$ \\
\hline $72 \% \mathrm{Ar}+28 \% \mathrm{He}$ & $\mathrm{a}$ & 14 & 1.5 & 7.2 & 5 & 133 & $6.7 \pm 7 \%$ & $6.9 \pm 12 \%$ & $15.6 \pm 11 \%$ & $15.8 \pm 12 \%$ \\
$97 \% \mathrm{Ar}+3 \% \mathrm{H}_{2}$ & $\mathrm{~b}$ & 14 & 1.5 & 7.2 & 5 & 67 & $7.0 \pm 7 \%$ & $7.3 \pm 12 \%$ & $16.0 \pm 11 \%$ & $16.2 \pm 12 \%$ \\
$97 \% \mathrm{Ar}+3 \% \mathrm{H}_{2}$ & $\mathrm{c}$ & 14 & 1.5 & 7.2 & 5 & 133 & $7.1 \pm 7 \%$ & $7.4 \pm 12 \%$ & $16.2 \pm 11 \%$ & $16.5 \pm 12 \%$ \\
\hline
\end{tabular}

lines of neutral rare gases. By comparing the different spectral lines obtained under the same plasma conditions, we tested the physical stability of the deconvolution procedure. The obtained parameters, which are tied to plasma conditions, such as $T$ and $N$, are independent from the analyzed lines. Our calculated values of temperature from each spectral line and values obtained by Boltzmann and Saha equations are in very good agreement, within $\pm 7 \%$. The electron density calculated from each spectral line shows even better agreement with the values measured by interferometry, the agreement being within $\pm 5 \%$.

Taking into account the uncertainties of the line profile measurements and above mentioned, we estimate errors $\pm 12 \%$ for the $W_{\mathrm{e}}$ and $W_{\mathrm{i}}, \pm 15 \%$ for the $A$ parameter and $\pm 20 \%$ for $D$.

\section{Experiment}

The modified version of the linear low pressure pulsed arc (Djeniže et al. 1991, 1998, 2002; Milosavljević et al. 2000, 2001) has been used as a plasma source. Pulsed discharge was performed in a quartz discharge tube. The working gases were helium-argon $(28 \% \mathrm{He}+72 \% \mathrm{Ar})$ and hydrogen-argon $\left(3 \% \mathrm{H}_{2}+97 \% \mathrm{Ar}\right)$ mixtures. The used tube geometry and corresponding discharge conditions are presented in Table 1.

The spectroscopic observation of spectral lines has been made end-on along the axis of the discharge tube.

The line profiles were recorded by a step-by-step technique using a photomultiplier (EMI 9789 QB and EMI 9659B) and a grating spectrograph (Zeiss PGS-2, reciprocal linear dispersion $0.73 \mathrm{~nm} \mathrm{~mm}^{-1}$ in the first order) system. The instrumental $F W H M$ of $8 \mathrm{pm}$ was obtained by using narrow spectral lines emitted by the hollow cathode discharge. The spectrograph exit slit $(10 \mu \mathrm{m})$ with the calibrated photomultipliers was micrometrically traversed along the spectral plane in small wavelength steps (7.3 pm). The averaged photomultiplier signal (five shots in each position) was digitized using an oscilloscope, interfaced to a computer.

Plasma reproducibility was monitored by the ArI and Ar II line radiation and, also, by the discharge current using a Rogowski coil signal (it was found to be within $\pm 5 \%$ ).

The used deconvolution procedure in its details is described in Milosavljević \& Poparić (2001) and Milosavljević (2001). It includes a new advanced numerical procedure for deconvolution of theoretical asymmetric convolution integral of a Gaussian and a plasma broadened spectral line profile $j_{A, R}(\lambda)$ for spectral lines. This method gives complete information on the plasma parameters from a single recorded spectral line.
The method determines all broadening $\left(W_{\mathrm{t}}, W_{\mathrm{e}}, W_{\mathrm{i}}, A\right.$ and $\left.D\right)$ and plasma parameters ( $N$ and $T$ ) self-consistently and directly from the shape of spectral lines without any assumptions or prior knowledge, making it useful in astrophysics. All one needs to know is the instrumental width of the spectrometer. The measured profiles are the results of convolution with the Lorentzian Stark and Gaussian profiles caused by Doppler and instrumental broadening (Griem 1974). Van der Waals and resonance broadenings (Griem 1974) were estimated to be smaller by more than an order of magnitude in comparison to Stark, Doppler and instrumental broadenings. The deconvolution procedure was computed using the least Chi-square function (Milosavljević \& Poparić 2001).

The absence of self-absorption was checked using the method presented in Djeniže \& Bukvić (2001).

The plasma parameters were determined independently using standard diagnostics methods. Thus, the electron temperature was determined from the ratios of the relative line intensities of seven Ar I spectral lines $(415.859 \mathrm{~nm}, 416.418 \mathrm{~nm}$, $419.103 \mathrm{~nm}, \quad 419.832 \mathrm{~nm}, \quad 420.067 \mathrm{~nm}, \quad 425.936 \mathrm{~nm}$ and $426.627 \mathrm{~nm}$ ) to the five Ar II spectral lines $(335.093 \mathrm{~nm}$, $420.197 \mathrm{~nm}, 426.653 \mathrm{~nm}, 487.986 \mathrm{~nm}, 488.903 \mathrm{~nm})$ with an estimated error of $\pm 11 \%$, assuming the existence of LTE (Griem 1974). The necessary atomic data have been taken from NIST (2002). The electron density decay was measured using a well-known single wavelength $\mathrm{He}-\mathrm{Ne}$ laser interferometer technique for the $632.8 \mathrm{~nm}$ transition with an estimated error of $\pm 7 \%$. The electron densities $\left(N^{\exp }\right)$ and temperatures $\left(T^{\exp }\right)$, obtained at the moment when the line profiles were analyzed, are presented in Table 1 together with the $N^{\mathrm{D}}$ and $T^{\mathrm{D}}$ values obtained using the deconvolution procedure.

\section{Results and discussion}

The measured $N^{\exp }$ and $T^{\exp }$ decays are presented in Fig. 1 together with the averaged $N^{\mathrm{D}}$ and $T^{\mathrm{D}}$ values obtained using the line profile deconvolution procedure for five Ar I lines. One can conclude that the agreement among $T^{\exp }$ and $T^{\mathrm{D}}$ values is excellent (within $3 \%$ on average in the three plasmas investigated). This fact confirms the homogeneity of the investigated plasmas in the linear part of our light source (see Fig. 1 in Djeniže et al. 1998). In the case of the electron density, the situation is similar. The agreement among the two sets of the electron density decays ( $N^{\exp }$ and $N^{\mathrm{D}}$ ) is within the experimental accuracy of $\pm 7 \%$ and uncertainties $( \pm 12 \%)$ of the results obtained with the deconvolution procedure. 


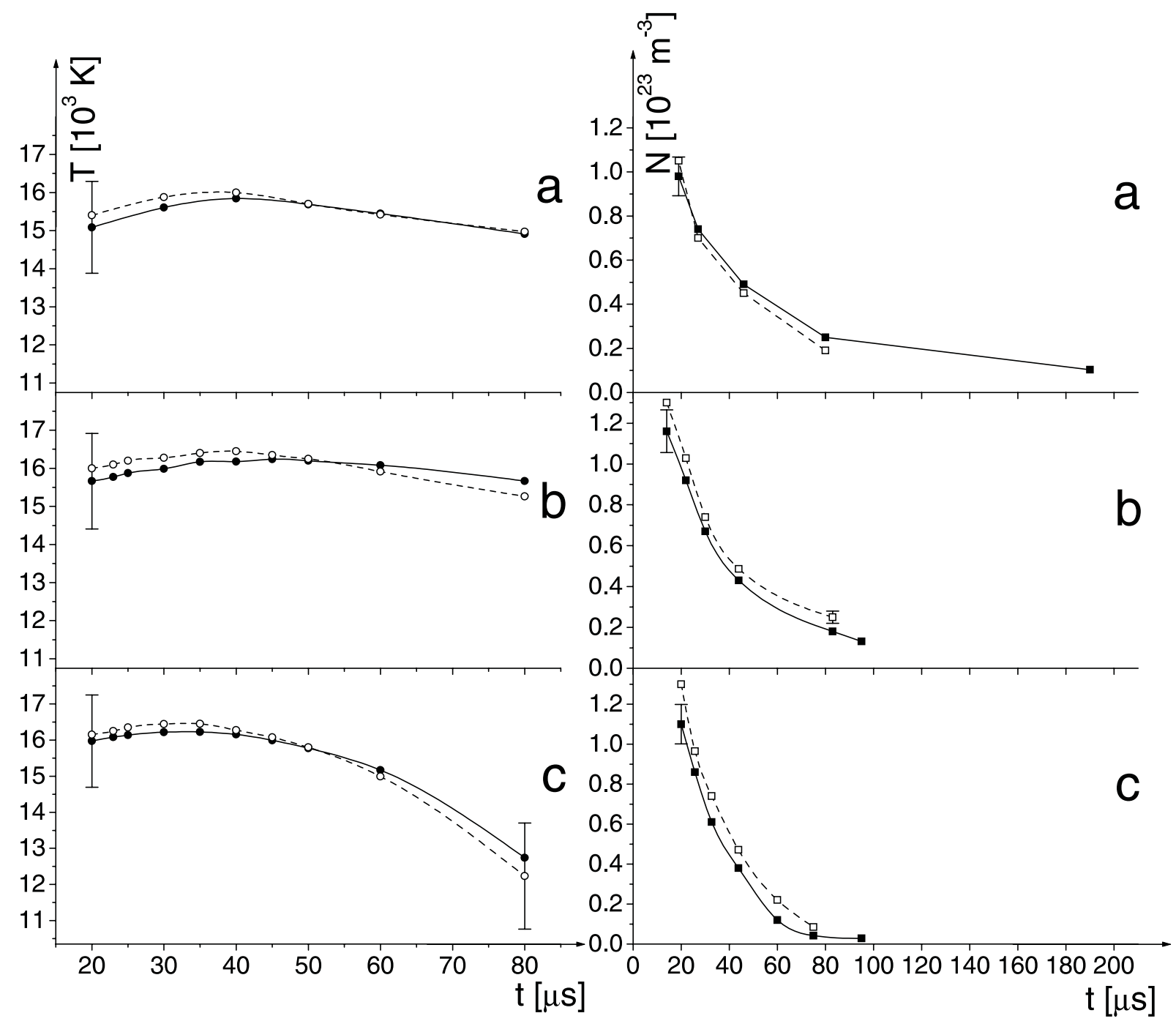

Fig. 1. Electron temperature $(T)$ and density $(N)$ decays. Full lines represent measured data using independent experimental techniques. Dashed lines represent plasma parameters obtained using our line deconvolution procedure in various plasmas (see a, b and c in Table 1). Error bars represent estimated accuracies of the measurements $( \pm 11 \%$ and $\pm 7 \%$ for $T$ and $N$, respectively) and deconvolutions $( \pm 12 \%)$.

The plasma broadening parameters $\left(W_{\mathrm{t}}^{\exp }, W_{\mathrm{e}}^{\exp }, W_{\mathrm{i}}^{\exp }\right.$, $A^{\exp }, D^{\exp }$ ) obtained using our deconvolution procedure of the recorded line profiles at measured $N^{\exp }$ and $T^{\exp }$ values are presented in Table 2 together with those of other authors. Theoretical (Griem 1974) predictions (index G) of the $W_{\mathrm{e}}$ and $A$ are also given. For the normalization of the $A^{\mathrm{G}}$ values to our electron density the well-known $N^{1 / 4}$ numerical factor (Griem 1974) was used.

In order to make the comparison among the measured $\left(W_{\mathrm{t}}^{\exp }\right)$ and calculated $\left(W_{\mathrm{t}}^{\mathrm{G}}\right)$ total (electron + ion) width values easier, the dependence of the ratio $W_{\mathrm{t}}^{\exp } / W_{\mathrm{t}}^{\mathrm{G}}$ on the electron temperature is presented graphically in Figs. 2 and 3. The $W_{\mathrm{t}}^{\mathrm{G}}$ (Griem 1974) values are calculated using Eq. (226) from Griem (1974).

Our broadening parameters $\left(W_{\mathrm{t}}^{\exp }\right)$ represent the first measured values at electron temperatures higher than $14000 \mathrm{~K}$.

The comparison of our $W_{\mathrm{t}}^{\exp }, W_{\mathrm{e}}^{\exp }$ and $A^{\exp }$ values with uniquely theoretical data (Griem 1974) was possible for only two transitions. Thus, in the case of the $419.832 \mathrm{~nm}$ Ar I spectral line Griem's (1974) theoretical $W_{\mathrm{t}}^{\mathrm{G}}$ values are about twice as high as the experimental $W_{t}^{\text {exp }}$ values (see Fig. 2). Also, the $W_{\mathrm{e}}^{\mathrm{G}}$ values are about twice as high as our $W_{\mathrm{e}}^{\exp }$ values. We think that the discrepancy between measured and theoretical values indicates that the atomic data used for calculations (Griem 1974) were unreliable. Our ion broadening parameters $\left(A^{\text {exp }}\right)$ overvalue the theoretical $\left(A^{\mathrm{G}}\right)$ values by about $26 \%$ and are multiplied 1.3-1.6 times with the ion-dynamical effect, depending on the discharge conditions. In the case of the $420.068 \mathrm{~nm}$ Ar I line all experimental $W_{\mathrm{t}}^{\text {exp }}$ values lie below Griem's (1974) values by about $20 \%$ on average (see Fig. 3). Our $W_{\mathrm{e}}^{\exp }$ values are about $20 \%$ smaller than the theoretical $W_{\mathrm{e}}^{\mathrm{G}}$ data. Our ion broadening parameters $\left(A^{\exp }\right)$ overvalue for about $65 \%$ the theoretical $\left(A^{\mathrm{G}}\right)$ values and are multiplied 1.3-1.6 times with the ion-dynamical effect, depending on the discharge conditions. Generally, the electron contribution to the total Stark width found experimentally is about $85 \%$ (on average) at about $16000 \mathrm{~K}$ electron temperature.

It turns out that $A^{\exp }$ values obtained by Jones et al. (1986, 1987) and Hahn \& Woltz (1990) for the $415.86 \mathrm{~nm}$ line agree well with ours. In the case of the $416.42 \mathrm{~nm}$ line, 
Table 2. The Ar I line broadening characteristics. Measured: total Stark $F W H M$ ( $W_{\mathrm{t}}^{\text {exp }}$ in pm within $\pm 12 \%$ accuracy), electron Stark width ( $W_{\mathrm{e}}^{\text {exp }}$ in pm within $\pm 12 \%$ accuracy), ion Stark width ( $W_{\mathrm{i}}^{\text {exp }}$ in pm within $\pm 12 \%$ accuracy), static ion broadening parameter $\left(A^{\text {exp }}\right.$, dimensionless within $\pm 15 \%$ accuracy) and ion-dynamic coefficient $\left(D^{\exp }\right.$, dimensionless within $\pm 20 \%$ accuracy) at measured electron temperature ( $T^{\exp }$ in $10^{3} \mathrm{~K}$ ) and electron density $\left(N^{\exp }\right.$ in $\left.10^{22} \mathrm{~m}^{-3}\right)$. Ref represents the values given in this work (Tw) and those used from other authors: KM, Kusz \& Mazur (1996); B, Bues et al. (1969); G, Gericke (1961); J, Jones et al. (1986); HW, Hahn \& Woltz (1990); A, Aparicio et al. (1998); P, Powell (1969); MM, Musielok et al. (1976); JP, Jones et al. (1987); M, Musielok (1994); Ch, Chapelle et al. (1967); Gr, Griem (1962). The index G denote theoretical data taken from Griem (1974) at a given $T$ and $N$.

\begin{tabular}{|c|c|c|c|c|c|c|c|c|c|c|c|}
\hline Multiplet & $\lambda(\mathrm{nm})$ & $T^{\exp }$ & $N^{\exp }$ & $W_{\mathrm{t}}^{\exp }$ & $W_{\mathrm{e}}^{\exp }$ & $W_{\mathrm{i}}^{\exp }$ & $A^{\exp }$ & $D^{\exp }$ & Ref. & $W_{\mathrm{e}}^{\mathrm{G}}$ & $A^{\mathrm{G}}$ \\
\hline \multirow[t]{6}{*}[3/2]{$_{1}^{\mathrm{o}}-[1 / 2]_{\mathrm{o}}$} & \multirow[t]{6}{*}{419.83} & 15.6 & 6.7 & 130 & 112 & 18 & 0.143 & 1.347 & Tw & 223 & 0.113 \\
\hline & & 16.0 & 7.0 & 137 & 117 & 20 & 0.145 & 1.656 & Tw & 235 & 0.114 \\
\hline & & 16.2 & 7.1 & 139 & 119 & 20 & 0.145 & 1.649 & $\mathrm{Tw}$ & 239 & 0.114 \\
\hline & & 11.1 & 0.4 & 3.3 & & & & & $\mathrm{KM}$ & & \\
\hline & & 12.4 & 7.3 & 120 & & & & & $\mathrm{~B}$ & & \\
\hline & & 14.0 & 1.0 & 23 & & & & & $\mathrm{G}$ & & \\
\hline \multirow[t]{12}{*}[3/2]{$_{2}^{o}-[3 / 2]_{2}$} & \multirow[t]{12}{*}{415.86} & 15.6 & 6.7 & 132 & 114 & 18 & 0.143 & 1.332 & Tw & & \\
\hline & & 16.0 & 7.0 & 139 & 119 & 20 & 0.146 & 1.638 & $\mathrm{Tw}$ & & \\
\hline & & 16.2 & 7.1 & 143 & 122 & 21 & 0.147 & 1.624 & Tw & & \\
\hline & & 11.9 & 6.2 & 121 & & & 0.127 & & $\mathrm{~J}$ & & \\
\hline & & 11.9 & 6.2 & 112 & & & 0.125 & & HW & & \\
\hline & & 13.5 & 10.0 & 246 & & & & & A & & \\
\hline & & 12.7 & 9.4 & 173 & & & & & $\mathrm{~B}$ & & \\
\hline & & 11.4 & 4.6 & 110 & & & & & $\mathrm{G}$ & & \\
\hline & & 14.0 & 1.0 & 18.3 & & & & & $\mathrm{P}$ & & \\
\hline & & 12.5 & 9.2 & 190 & & & & & MM & & \\
\hline & & 11.9 & 6.2 & 123 & & & 0.127 & & $\mathrm{JP}$ & & \\
\hline & & 13.4 & 4.5 & 107 & & & & & M & & \\
\hline \multirow[t]{11}{*}[3/2]{$_{2}^{o}-[3 / 2]_{1}$} & \multirow[t]{11}{*}{416.42} & 15.6 & 6.7 & 126 & 109 & 17 & 0.140 & 1.357 & Tw & & \\
\hline & & 16.0 & 7.0 & 134 & 115 & 19 & 0.142 & 1.664 & $\mathrm{Tw}$ & & \\
\hline & & 16.2 & 7.1 & 134 & 115 & 19 & 0.142 & 1.663 & $\mathrm{Tw}$ & & \\
\hline & & 11.9 & 6.2 & 97 & & & 0.196 & & HW & & \\
\hline & & 13.8 & 14.5 & 332 & & & & & $\mathrm{Ch}$ & & \\
\hline & & 11.1 & 0.4 & 3.7 & & & & & $\mathrm{KM}$ & & \\
\hline & & 12.7 & 9.4 & 171 & & & & & B & & \\
\hline & & 11.4 & 4.6 & 100 & & & & & G & & \\
\hline & & 14.0 & 1.0 & 18.1 & & & & & $\mathrm{P}$ & & \\
\hline & & 10.6 & 2.6 & 59.6 & & & & & MM & & \\
\hline & & 11.5 & 5.1 & 96 & & & & & M & & \\
\hline \multirow[t]{7}{*}[3/2]{$_{1}^{\mathrm{o}}-[3 / 2]_{2}$} & \multirow[t]{7}{*}{426.63} & 15.6 & 6.7 & 127 & 110 & 27 & 0.132 & 1.380 & Tw & & \\
\hline & & 16.0 & 7.0 & 130 & 113 & 27 & 0.132 & 1.712 & $\mathrm{Tw}$ & & \\
\hline & & 16.2 & 7.1 & 136 & 118 & 28 & 0.134 & 1.689 & $\mathrm{Tw}$ & & \\
\hline & & 11.9 & 6.2 & 126 & & & 0.076 & & HW & & \\
\hline & & 11.4 & 4.6 & 110 & & & & & G & & \\
\hline & & 14.0 & 1.0 & 17.9 & & & & & $\mathrm{P}$ & & \\
\hline & & 12.6 & 9.9 & 240 & & & & & M & & \\
\hline \multirow[t]{9}{*}[3/2]{$_{2}^{\mathrm{o}}-[5 / 2]_{3}$} & \multirow[t]{9}{*}{420.07} & 15.6 & 6.7 & 138 & 119 & 19 & 0.140 & 1.325 & $\mathrm{Tw}$ & 153 & 0.085 \\
\hline & & 16.0 & 7.0 & 143 & 123 & 20 & 0.142 & 1.636 & $\mathrm{Tw}$ & 162 & 0.085 \\
\hline & & 16.2 & 7.1 & 147 & 126 & 21 & 0.142 & 1.624 & $\mathrm{Tw}$ & 165 & 0.085 \\
\hline & & 13.8 & 14.5 & 324 & & & & & $\mathrm{Ch}$ & & \\
\hline & & 11.1 & 0.4 & 2.8 & & & & & $\mathrm{KM}$ & & \\
\hline & & 12.7 & 9.4 & 155 & & & & & $\mathrm{~B}$ & & \\
\hline & & 11.4 & 4.6 & 100 & & & & & G & & \\
\hline & & 12.6 & 9.2 & 180 & & & & & GR & & \\
\hline & & 13.4 & 4.5 & 94 & & & & & M & & \\
\hline
\end{tabular}




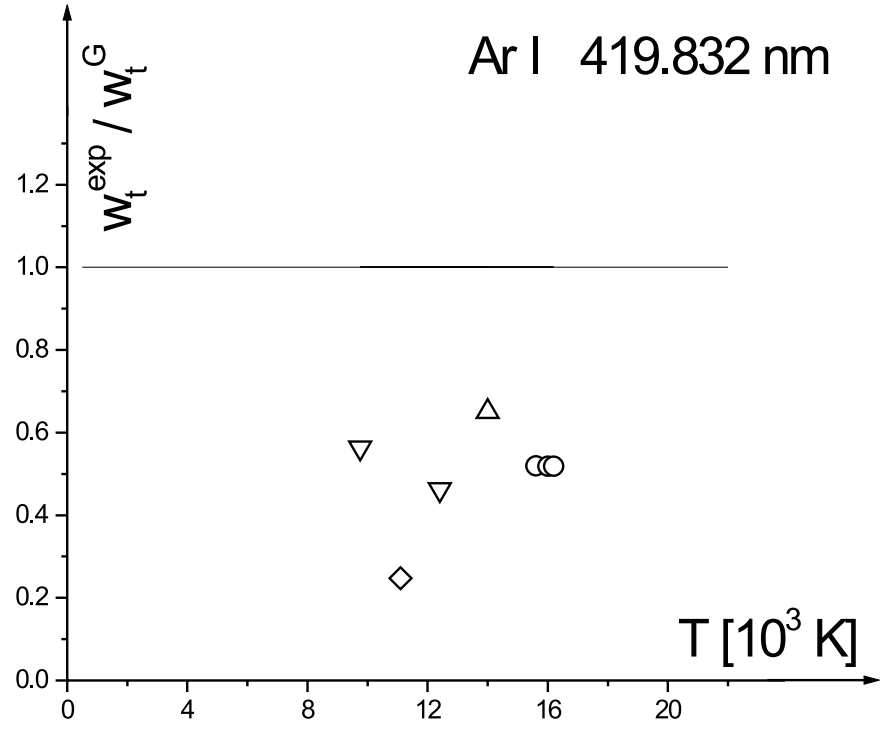

Fig. 2. Ratios of the experimental total Stark $F W H M\left(W_{\mathrm{t}}^{\exp }\right)$ to the theoretical $\left(W_{\mathrm{t}}^{\mathrm{G}}\right)$ predictions (Griem 1974) vs. electron temperature for $\lambda=419.832 \mathrm{~nm} . \bigcirc, \diamond, \nabla$ and $\Delta$ represent our experimental data and those from Kusz \& Mazur (1996), Bues et al. (1969) and Gericke (1961), respectively.

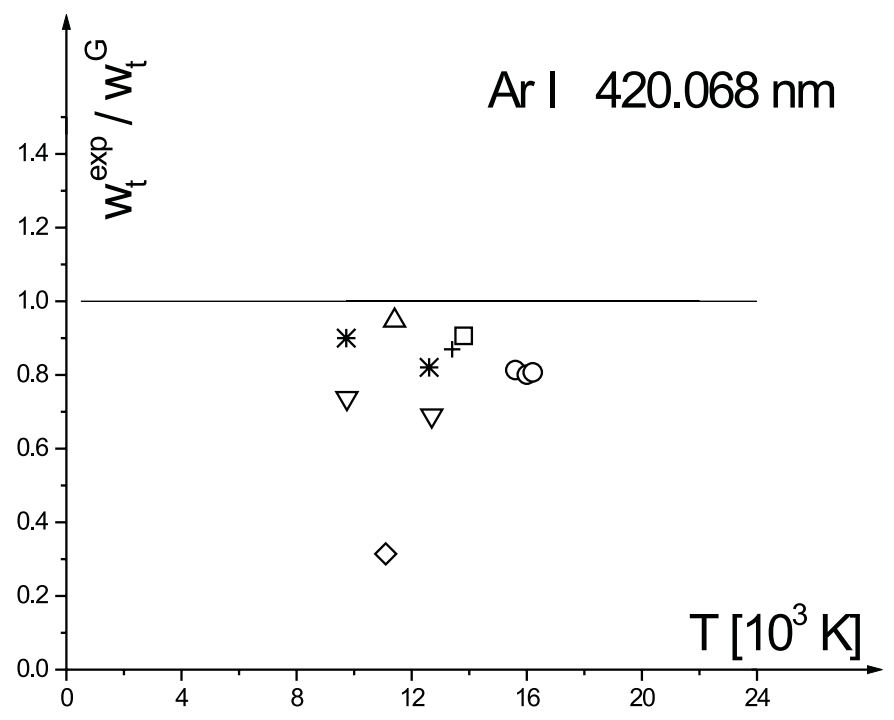

Fig. 3. Ratios of the experimental total Stark $F W H M\left(W_{\mathrm{t}}^{\mathrm{exp}}\right)$ to the theoretical $\left(W_{\mathrm{t}}^{\mathrm{G}}\right)$ predictions (Griem 1974) vs. electron temperature for $\lambda=420.068 \mathrm{~nm} . \bigcirc, \square, \diamond, \nabla, \Delta, *$ and + represent our experimental data and those from Chapelle et al. (1967), Kusz \& Mazur (1996), Bues et al. (1969), Gericke (1961), Griem (1962) and Musielok (1994), respectively.

Hahn \& Woltz (1990) have found $A^{\exp }$ higher than ours (see Table 2). Direct comparison of our $W_{\mathrm{t}}^{\exp }$ values with other experimental data for the $415.86 \mathrm{~nm}, 416.42 \mathrm{~nm}$ and $426.63 \mathrm{~nm}$ lines is impossible, because of the various plasma conditions in the experiments. But, taking into account the approximative normalization factor $\left(W_{\mathrm{t}} / N\right)$ we have found a tolerable scatter for the mentioned transitions among $W_{\mathrm{t}} / N$ experimental values (within 15\%-38\%). The only exceptions are very low $W_{\mathrm{t}}$ values from Kusz \& Mazur (1996) which are about twice as small as ours and the $W_{\mathrm{t}} / N$ values of other authors.

\section{Conclusion}

It is shown that the line deconvolution procedure described by Milosavljević \& Poparić (2001), applied to Ar I line profiles, gives convenient plasma parameters $(N$ and $T)$ at about $16000 \mathrm{~K}$ electron temperature and $7 \times 10^{22} \mathrm{~m}^{-3}$ electron density. We recommend this method for plasma diagnostic purposes for the case of optically thin plasmas.

We have found clear influence of the quasi-static ion and ion-dynamical effects on the investigated spectral line shapes. They play a much more important role than the semiclassical theory provides. The observed ion-dynamical effect, at our plasma conditions, multiplies the quasi-static ion contribution by up to a factor of 1.6. This is of importance for the use of these ArI lines for astrophysical plasma modeling or for diagnostics.

Acknowledgements. This work is a part of the project "Determination of the atomic parameters on the basis of the spectral line profiles" supported by the Ministry of Science, Technologies and Development of the Republic of Serbia. S. Djeniže is grateful to the Foundation “Arany János Közalapitvány” Budapest, Hungary.

\section{References}

Aparicio, J. A., Pérez, C., del Val, et al. 1998, J. Phys. B, 31, 4909

Barnard, A. J., Cooper, J., \& Smith, E. W. 1974, J. Quant. Spec. Radiat. Transf., 14, 1025

Bues, L., Haag, T., \& Richter, J. 1969, A\&A, 2, 249

Chapelle, J., Cabonne, Sy. A., Cabanners, F., \& Blandin, J. 1967, J. Quant. Spec. Radiat. Transf., 8, 1201; 1967, C.R.H. Acad. Sci. Ser. B, 264, 853

Djeniže, S., Srećković, A., Labat, J., Konjević, R., \& Popović, L. Č. 1991, Phys. Rev. A, 44, 410

Djeniže, S., Milosavljević, V., \& Srećković, A. 1998, J. Quant. Spec. Radiat. Transf., 59, 71

Djeniže, S., Milosavljević, V., \& Dimitrijević, M. S. 2002, A\&A, 382, 359

Djeniže, S., \& Bukvić, S. 2001, A\&A, 365, 252

Friedman, S. D., Howk, J. C., Andersson, B.-G., et al. 2000, ApJ, 538, L39

Gericke, W. E. 1961, Z. Astrophys., 53, 68

Griem, H. R. 1962, Phys. Rev., 128, 515

Griem, H. R. 1974, Spectral Line Broadening by Plasmas (New York: Acad. Press)

Hahn, D. T., \& Woltz, A. L. 1990, Phys. Rev. A, 42, 1450

Jenkins, E. B., Oegerle, W. R., Gry, C., et al. 2000, ApJ, 538, L81

Jones, D. W., Wiese, L. W., \& Woltz, A. L. 1986, Phys. Rev. A, 34, 450

Jones, D. W., Pichler, G., \& Wiese, W. L. 1987, Phys. Rev. A, 35, 2585

Kelleher, D. E. 1981, J. Quant. Spec. Radiat. Transf., 25, 191

Konjević, N., Lesage, A., Fuhr, J. R., \& Wiese, W. L. 2002, J. Phys. Chem. Ref. Data, 31, 819

Kruk, J. W., Howk, J. C., André, M., et al. 2002, ApJS, 140, 19

Kusz, J., \& Mazur, D. 1996, in Spectral line shapes, ed. M. Zoppi, L. Ulivi, 9, 323

Lehner, N., Sembach, K. R., Dufton, P. L., Rolleston, W. R. J., \& Keenan, F. P. 2002, ApJ, 551, 781

Lesage, A., \& Fuhr, J. R. 1999, Bibliography on Atomic Line Shapes and Shifts (Apr. 1992 - Jun. 1999), Observatoire de Paris 
Levshakov, S. A., Kegel, W. H., \& Agafonova, I. I. 2001, A\&A, 373, 836

Levshakov, S. A., Dessauges-Zavadsky, M., D’Odorico, S., \& Molaro, P. 2002, ApJ, 565, 696

Mallouris, C., Welty, D. E., York, D. G., et al. 2001, ApJ, 558, 133

Milosavljević, V., Djeniže, S., Dimitrijević, M. S., \& Popović, L. Č. 2000, Phys. Rev. E, 62, 4137

Milosavljević, V., \& Poparić, G. 2001, Phys. Rev. E, E63, 036404

Milosavljević, V. 2001, Ph.D. Thesis, University of Belgrade, Faculty of Physics, Belgrade (unpublished)

Milosavljević, V., Dimitrijević, M. S., \& Djeniže, S. 2001, ApJS, 135, 115

Milosavljević, V., \& Djeniže, S. 2002a, A\&A, 393, 721
Milosavljević, V., \& Djeniže, S. 2002b, New Astron., 7, 543

Milosavljević, V., \& Djeniže, S. 2002c, Phys. Lett. A, 305/1-2, 70

Milosavljević, V., \& Djeniže, S. 2003, A\&A, 398, 1179

Musielok, B., Musielok, J., \& Wujec, T. 1976, Zesz Nauk. Wyzsz. Szk. Pedagog. Opolu., Fiz., 17, 63

Musielok, J. 1994, Acta Phys. Po. A, 86, 315

NIST, Atomic Spectra Data Base Lines (wavelength order) 2002 http://physics.nist.gov

Powell, W. R. 1969, Diss. Abstr. B, 29, 3030

Richter, P., Sembach, K. R., Wakker, B. P., et al. 2001, ApJ, 559, 318

Weaver, H. A., Feldman, P. D., Combi, M. R., et al. 2002, ApJ, 576, L95 